\title{
Distributed Bio-Oil Reforming
}

2005 DOE Hydrogen, Fuel Cells \& Infrastructure Technologies Program Review

R. J. Evans, S. Czernik,

R. French, Kim Magrini

National Renewable Energy Laboratory

May 23-26, 2005

This presentation does not contain any proprietary or confidential information

Project ID\#PDP55 


\section{Overview}

Timeline

-Project start 2005 -Project end 2010 - 5\% complete

\section{Budget}

-FY05 \$100K

Partners

- CoorsTek
Production Barriers

A. Fuel Processor Capital

B. Fuel Processor Manufacturing

C. Operation \& Maintenance

D. Feedstock Issues

F. Control \& Safety

Target

Verify feasibility of achieving $\$ 3.60 /$ gge for renewable liquids distributed reforming 


\section{Objectives}

- Overall:

- Develop the necessary understanding of the process chemistry, compositional effects, catalyst chemistry and deactivation and regeneration strategy as a basis for process definition for automated distributed reforming

- FY05

- Determine the process performance of the catalytic reforming of whole bio-oil 


\section{Approach}

Biomass $\longrightarrow$ PYROLYSIS $\longrightarrow$ Bio-oil

Only the aqueous fraction

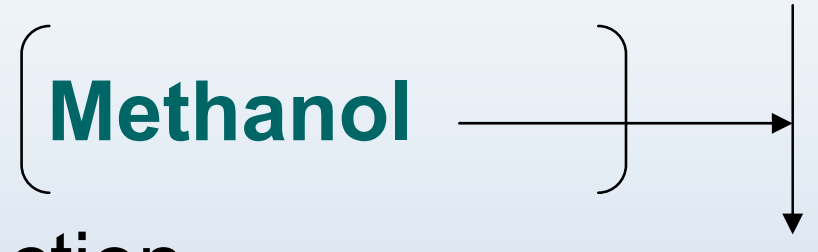
of bio-oil and directly coupled whole vapors

$\mathrm{H}_{2} \mathrm{O} \longrightarrow$ CATALYTIC STEAM REFORMING have been reformed to date. Approach is to show that bio-oil and blends with Methanol can be fed without excessive coking and develop a process to meet cost objectives.

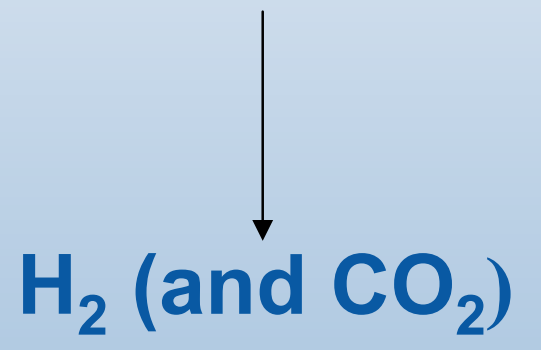




\section{Technical Accomplishments}

- Review of past work completed

- Report summarizes all aspects of producing hydrogen from biomass by pyrolysis/reforming studied in past projects

-Whole oil successfully run

- With $10 \% \mathrm{MeOH}$ addition, bio-oil processing was trouble free over short run durations (up to16 hrs)

- NREL catalysts shown to be effective

- Four catalyst compared with commercial

- Patents being filed 


\section{Bio-Oil}

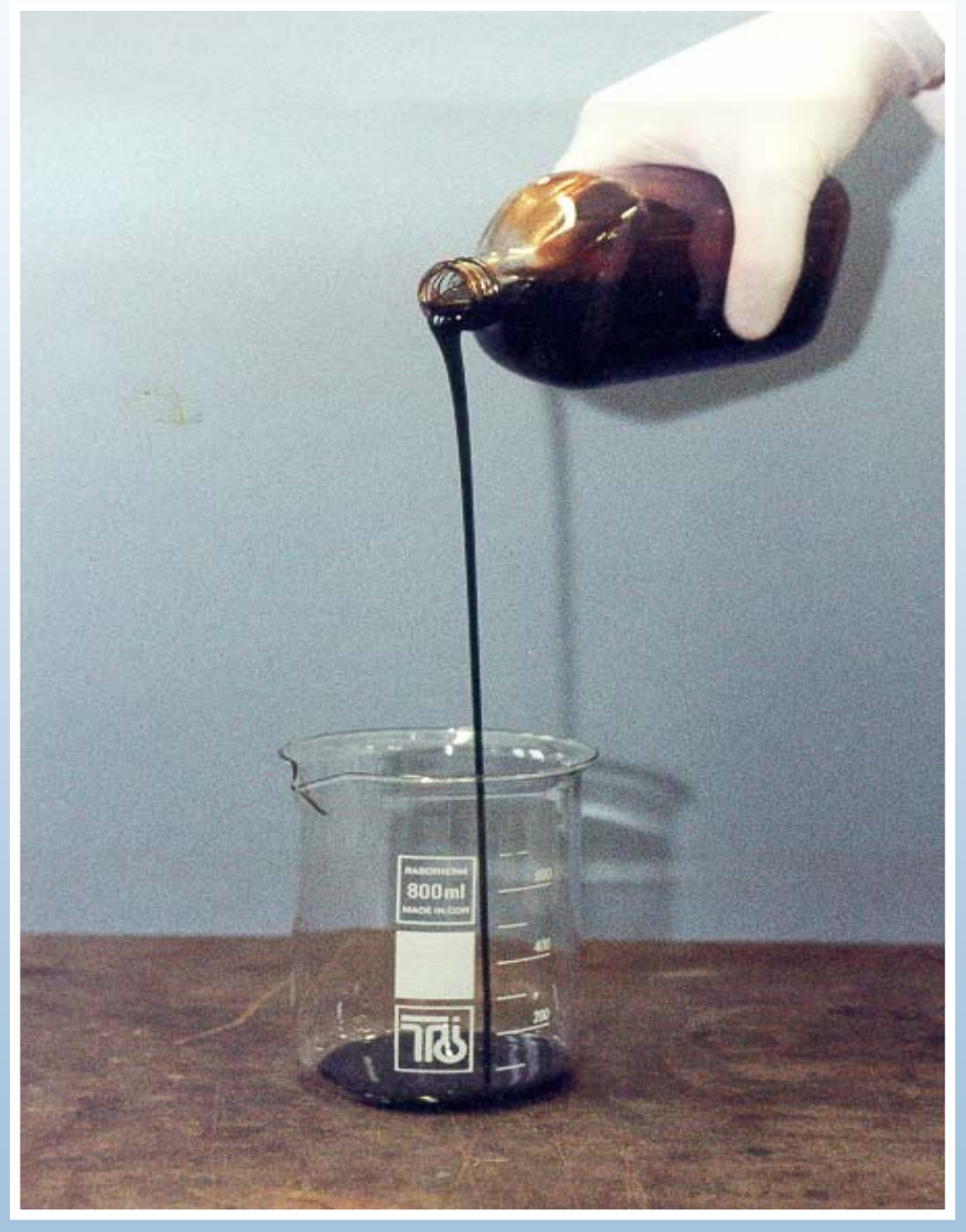

Bio-oil produced by fast pyrolysis of biomass with $75 \%$ yield is comprised of many oxygenated organic chemicals.

$>$ Properties

$>$ Not miscible with hydrocarbons

$>$ Heating value $\sim 17 \mathrm{MJ} / \mathrm{kg}$

$>$ Density $\sim 1.2 \mathrm{~kg} / \mathrm{l}$

$>$ Acid, $\mathrm{pH} \sim 2.5$

$>$ Pungent odour

$>$ Energy Density $\sim 5$ times green wood chips 


\section{Problem: Catalyst Attrition}

Liquid/Gas/Solid Feedstock

Fluidized

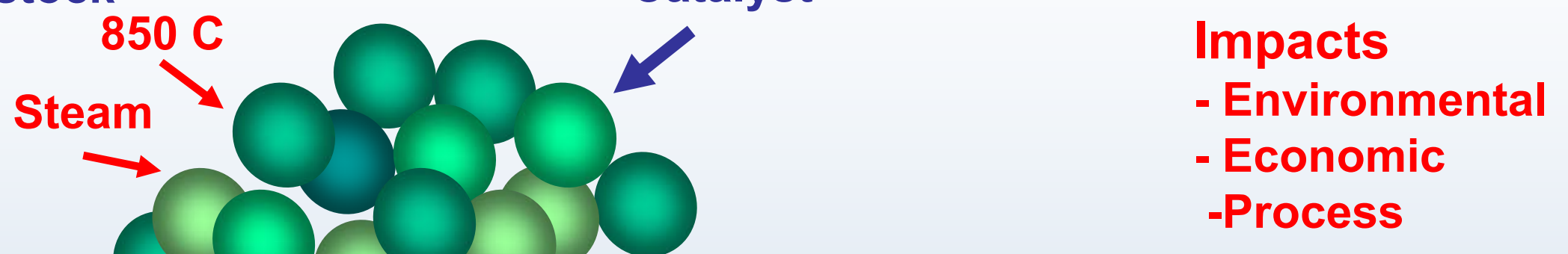

Impacts

- Environmental

- Economic -Process

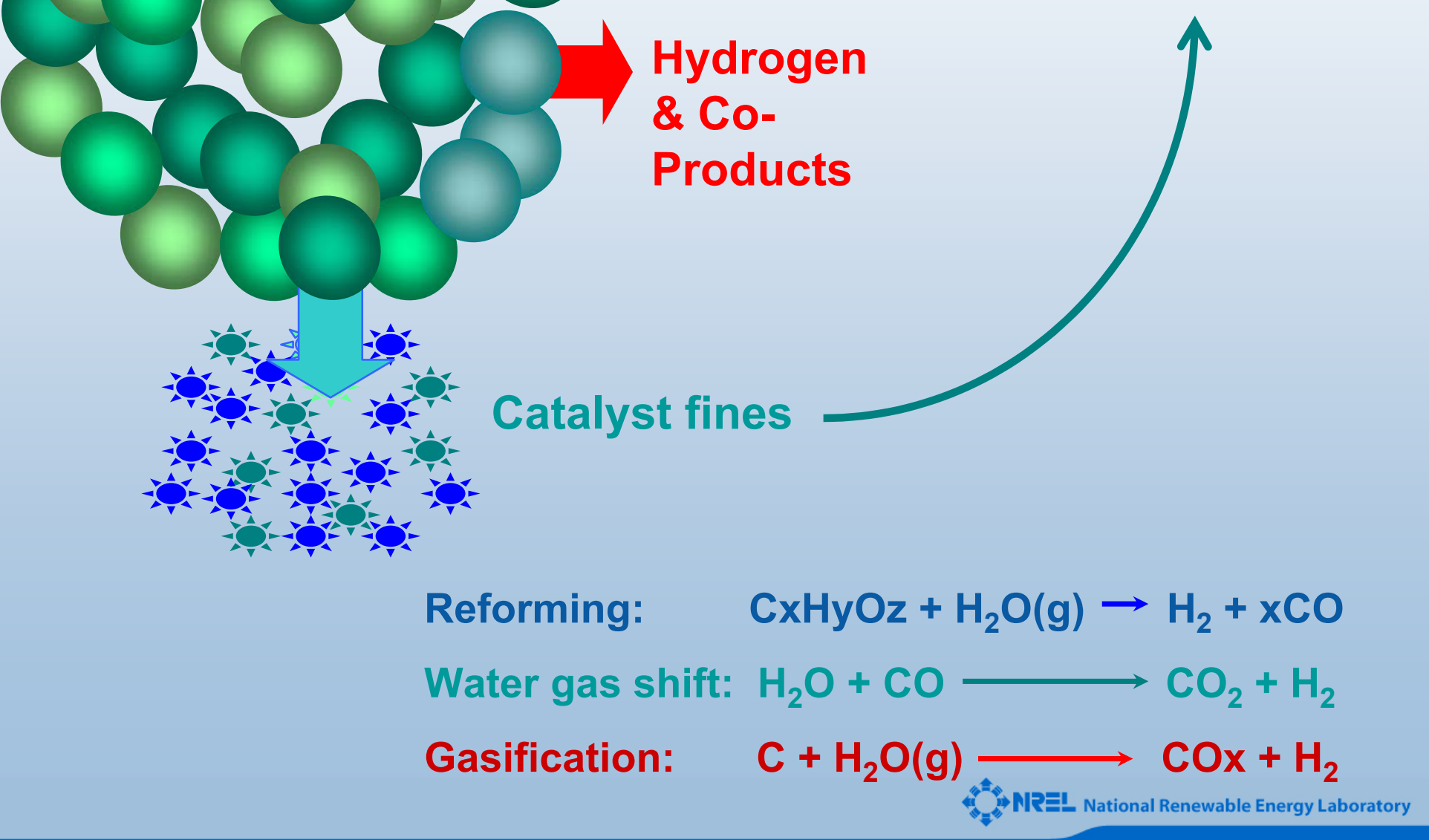




\section{Catalysts}

Whole Bio-oil on catalyst developed in prior work

$>$ Develop catalysts to reform light and heavy organics

$>$ New supports now available with potential novel activity

$>$ New catalyst rapid screening reactor available for whole oils provides capability for combinatorial screening

$>$ New catalyst characterization system available for determining catalyst deactivation, reactivation, and coking mechanisms

$>$ Develop low [Ni] and bimetallic ( $\mathrm{Ni}, \mathrm{Cr}$ ) reforming catalysts

$>$ Lifetime tests (activity steady $>500 \mathrm{~h}$ )

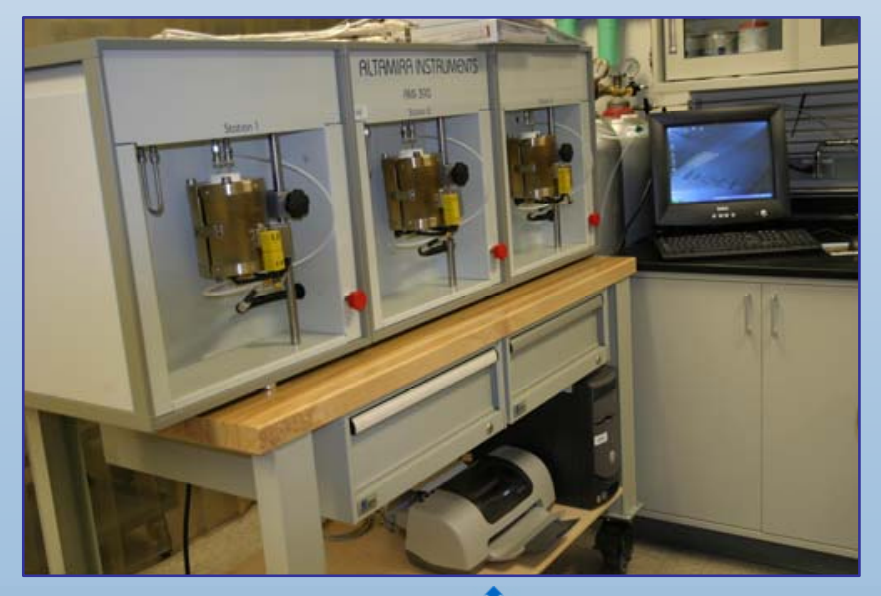

Test System 


\section{Bio-Oil Reformer System}

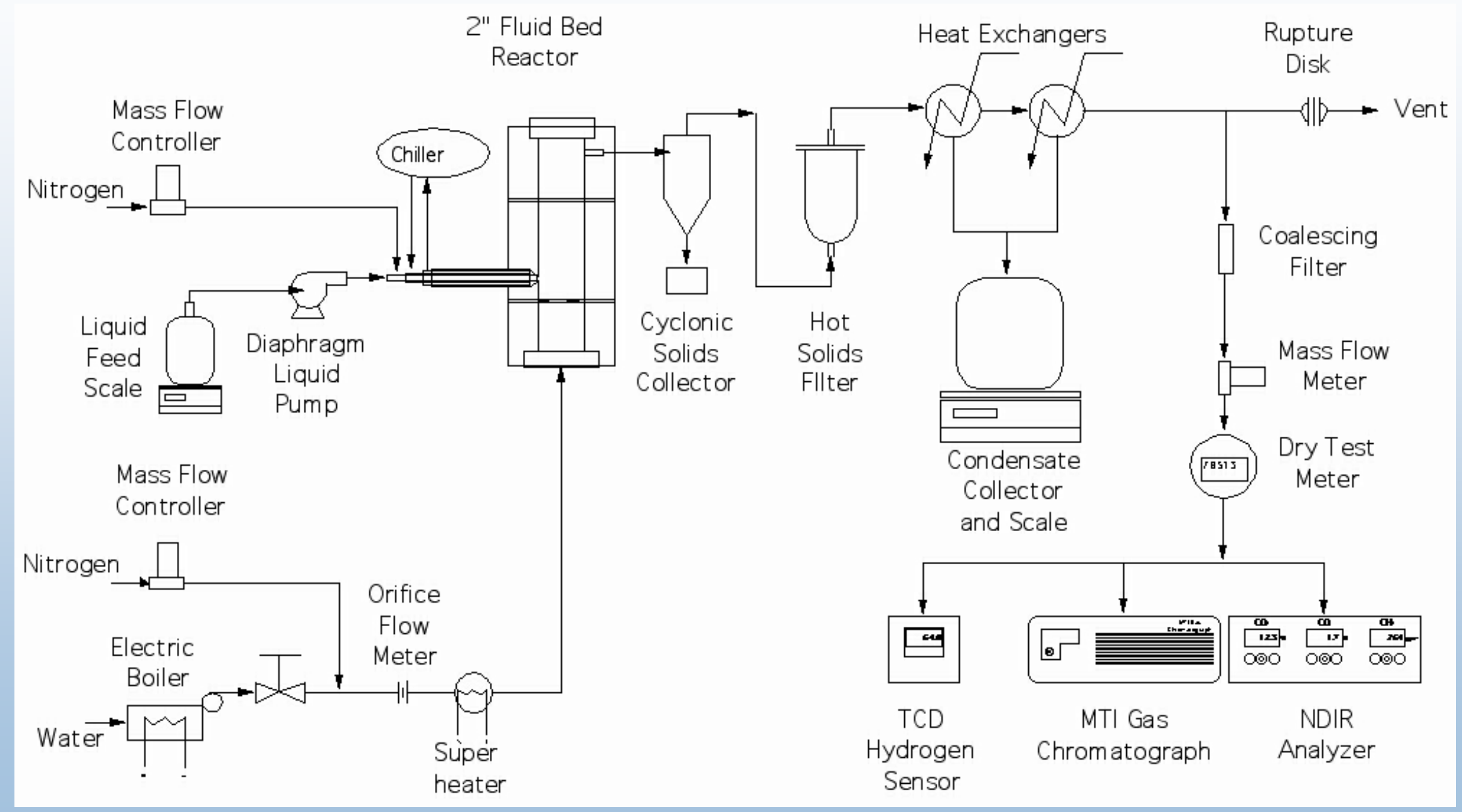




\section{Reforming Whole Bio-oil}

Gas Composition

C11-NK 850C
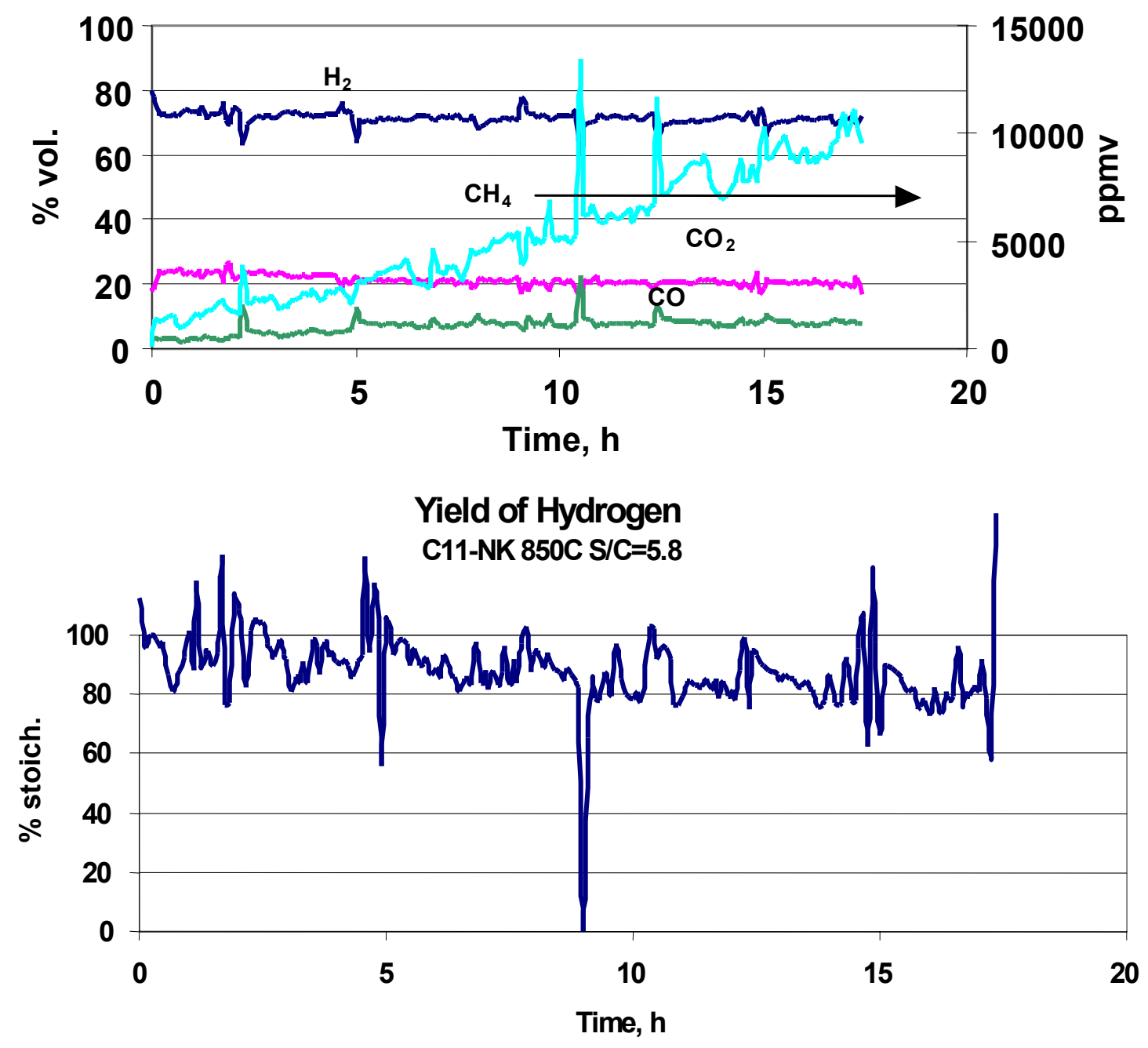


\section{Reforming Whole Bio-oil}

Gas Composition

NREL\#1, 850C, $S / C=5.8$

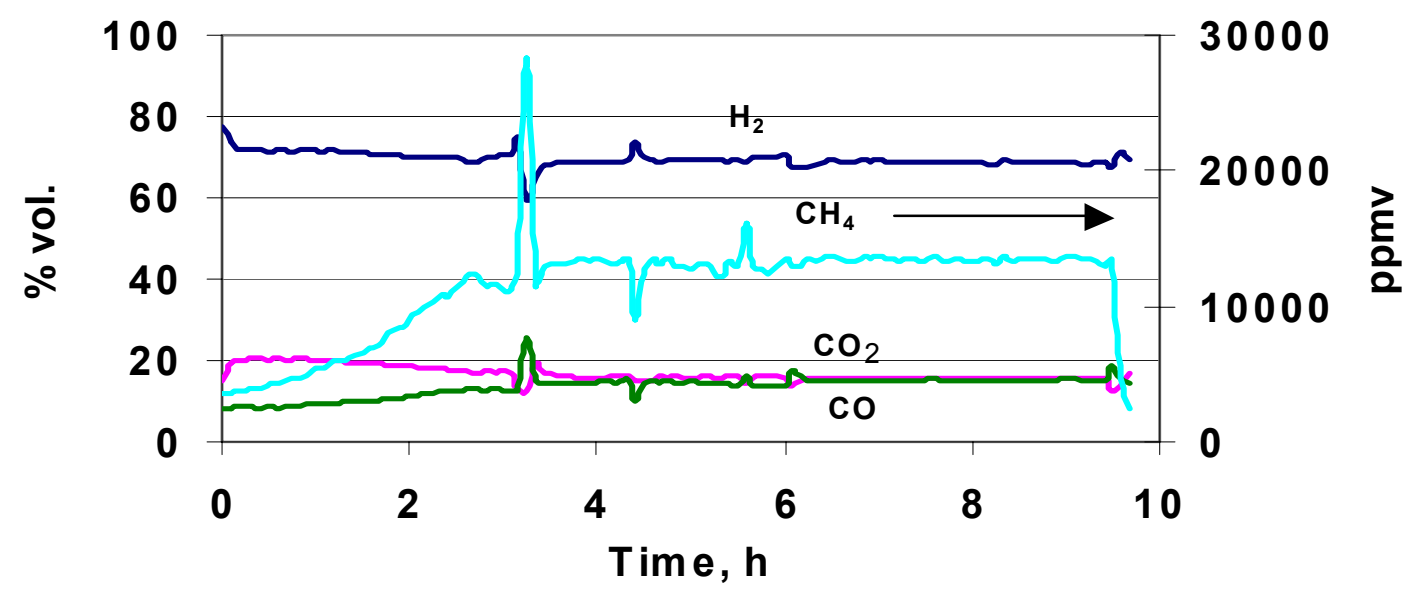

Yield of Hydrogen

NREL\#1, 850C, S/C=5.8

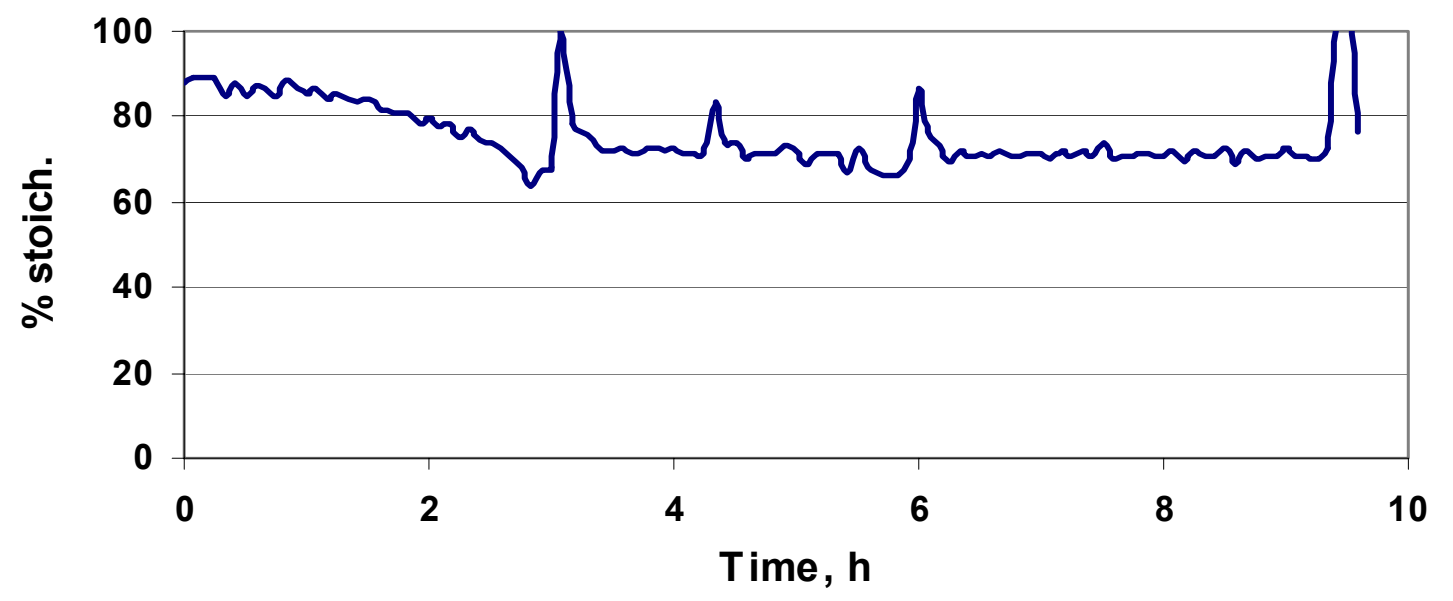




\section{Reforming Whole Bio-oil}

\section{Gas Composition}

NREL\#20, 850C, $S / C=5.8$

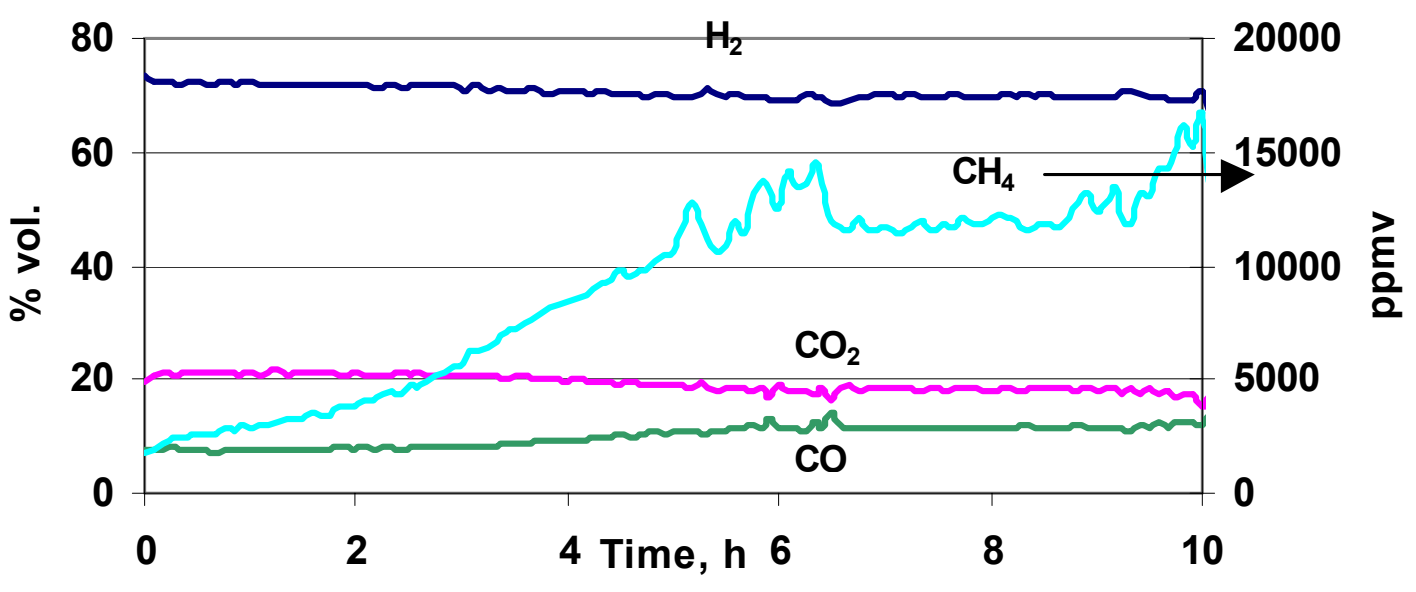

Yield of Hydrogen

NREL\#20, 850C, S/C=5.8

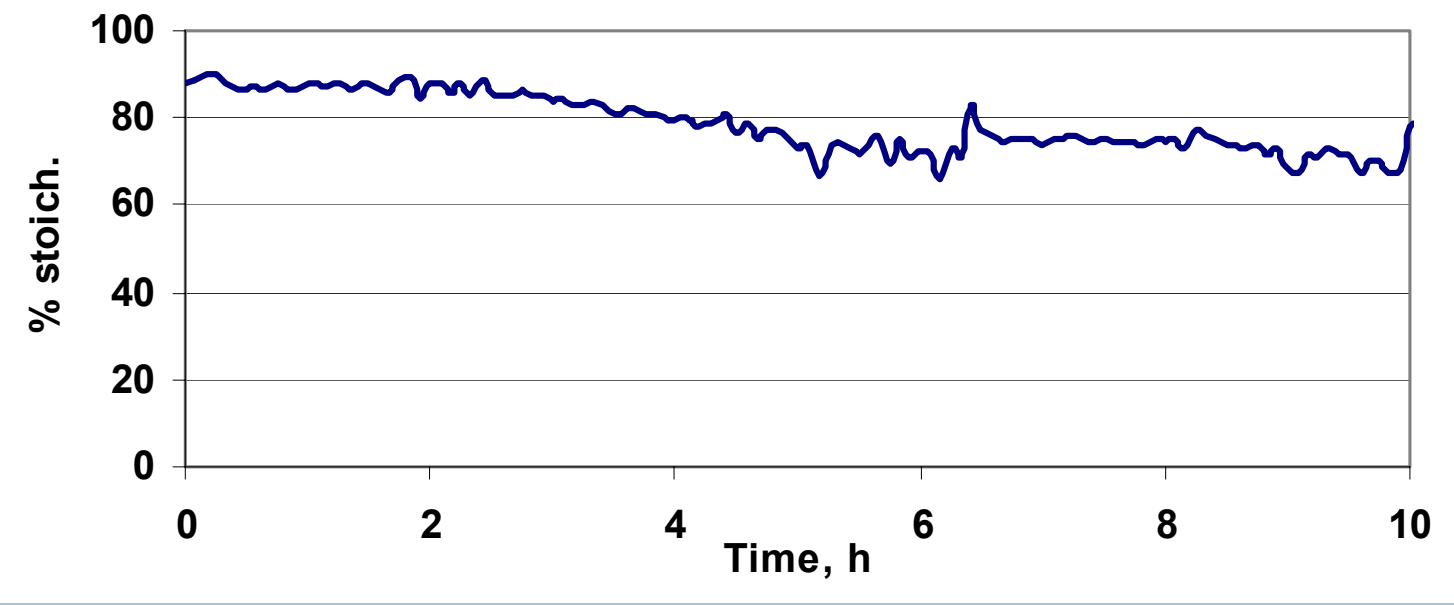




\section{Multivariate Data Analysis}

- Objective: develop a sensitive metric for catalyst performance to compare experiments

- Factor analysis used to determine correlated behavior among both independent (e.g., conditions) and dependent (e.g., products) variables

- Factor 1 represents $45 \%$ of variance in data set

-6 experiments $=10$ variables $\times 700$ readings 


\section{Variable Contributions}

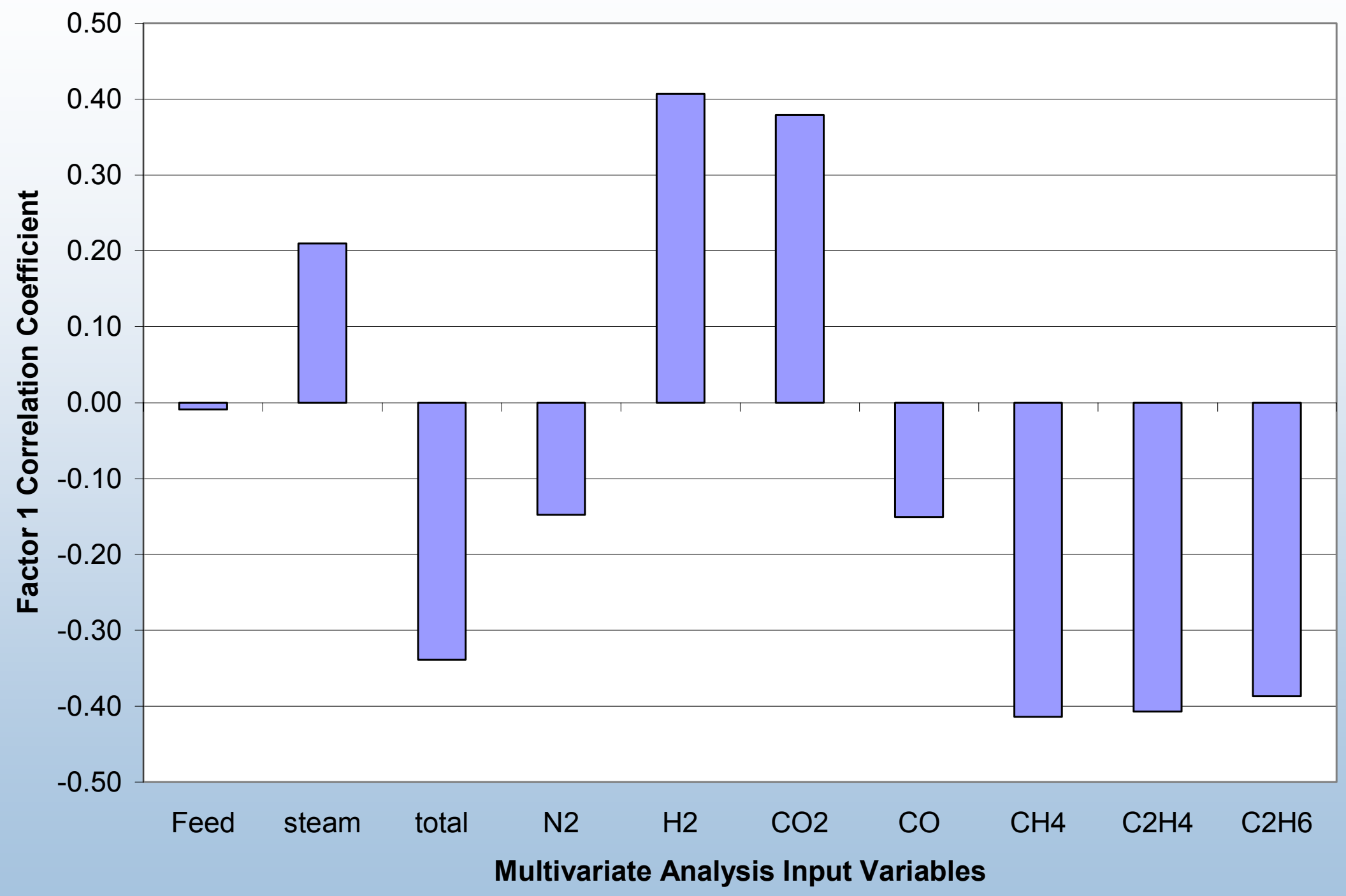




\section{Factor Analysis Run Comparison}

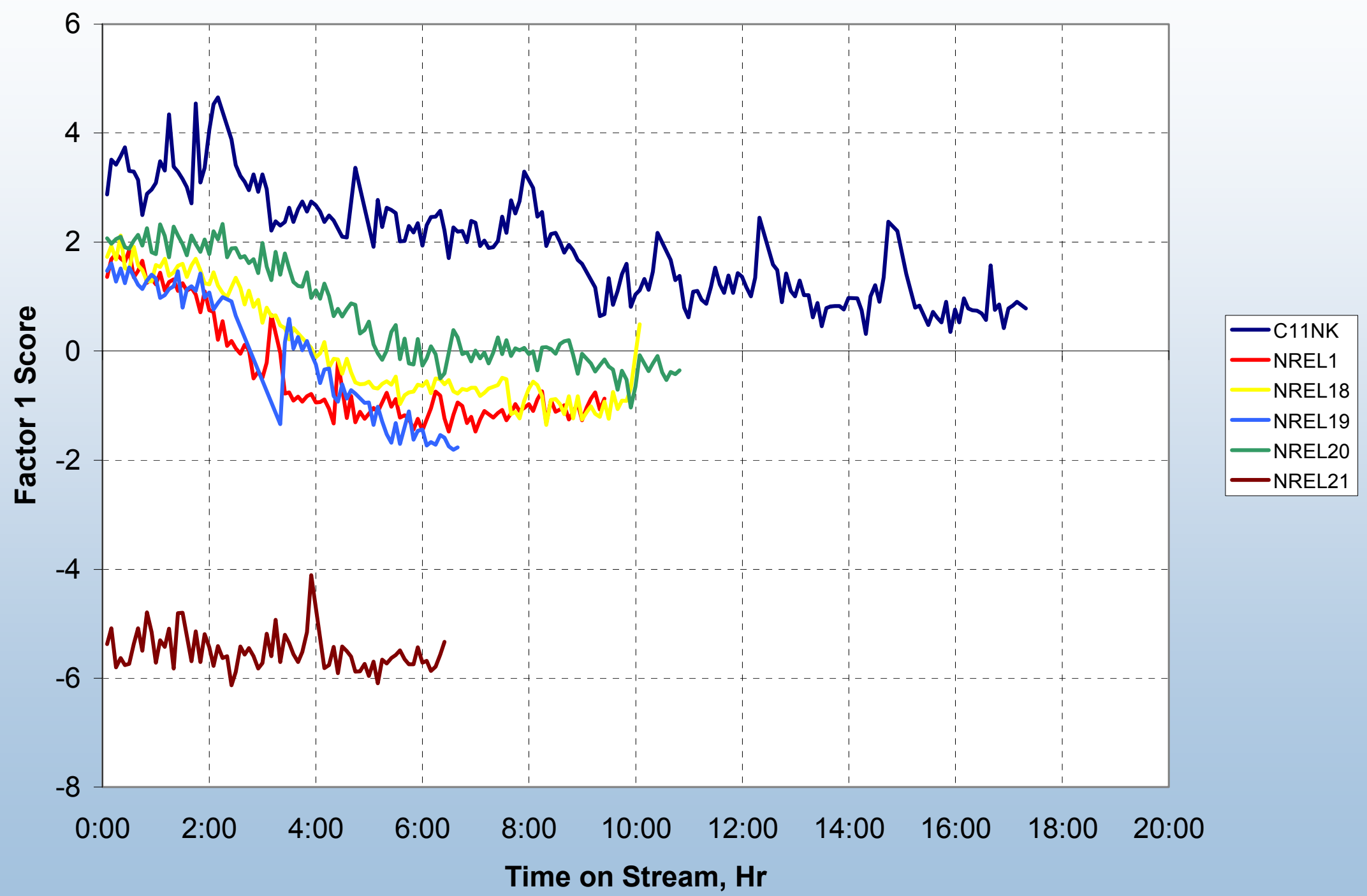




\section{Response to Reviewers Comments}

- Project should be combined with clearer focus on the program goals.

- Efforts combined in FY05. Historical approach based on co-products economics now switched to distributed reforming of bio-oil. New concepts in development to optimize this approach based on low temperature $\left(650^{\circ} \mathrm{C}\right)$ autothermal reforming.

- Limited progress made in FY04.

- Only limited progress was made in FY04 due to drastic budget cutbacks (\$200K in FY04 and \$100K in FY05).

- The conceptual design completed in 2004 is highly relevant to the distributed reforming challenge since it addresses catalyst and heat management in scale up to $250 \mathrm{~kg} \mathrm{H} 2 /$ day . 


\section{Future Work}

- FY06

- Develop low-temperature staged autothermal reforming systems based on homogeneous and heterogeneous partial oxidation, appropriate for small-scale automated systems

- New catalyst development for this new approach with emphasis on deactivation and poisoning

- FY07

- New reforming process reactor configuration

- Reaction Engineering

- 2008

- Bench scale bio-oil reforming tests for long-term testing

- 2009

- Scale up system development 


\section{New Distributed Bio-Oil Reforming Approach}

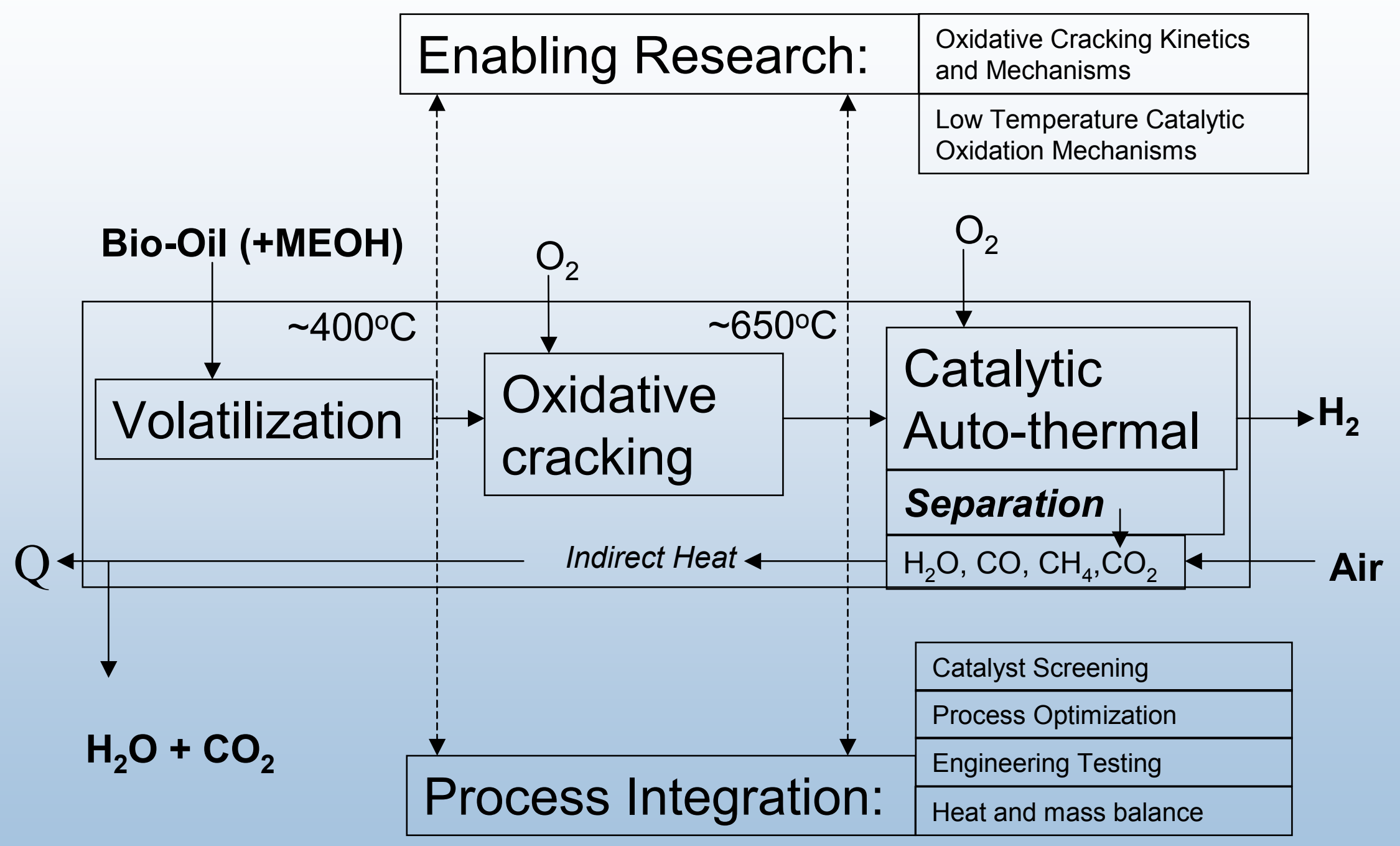




\section{Oxidative Cracking of Pyrolysis Products}

\section{M/z 128 = Naphthalene}

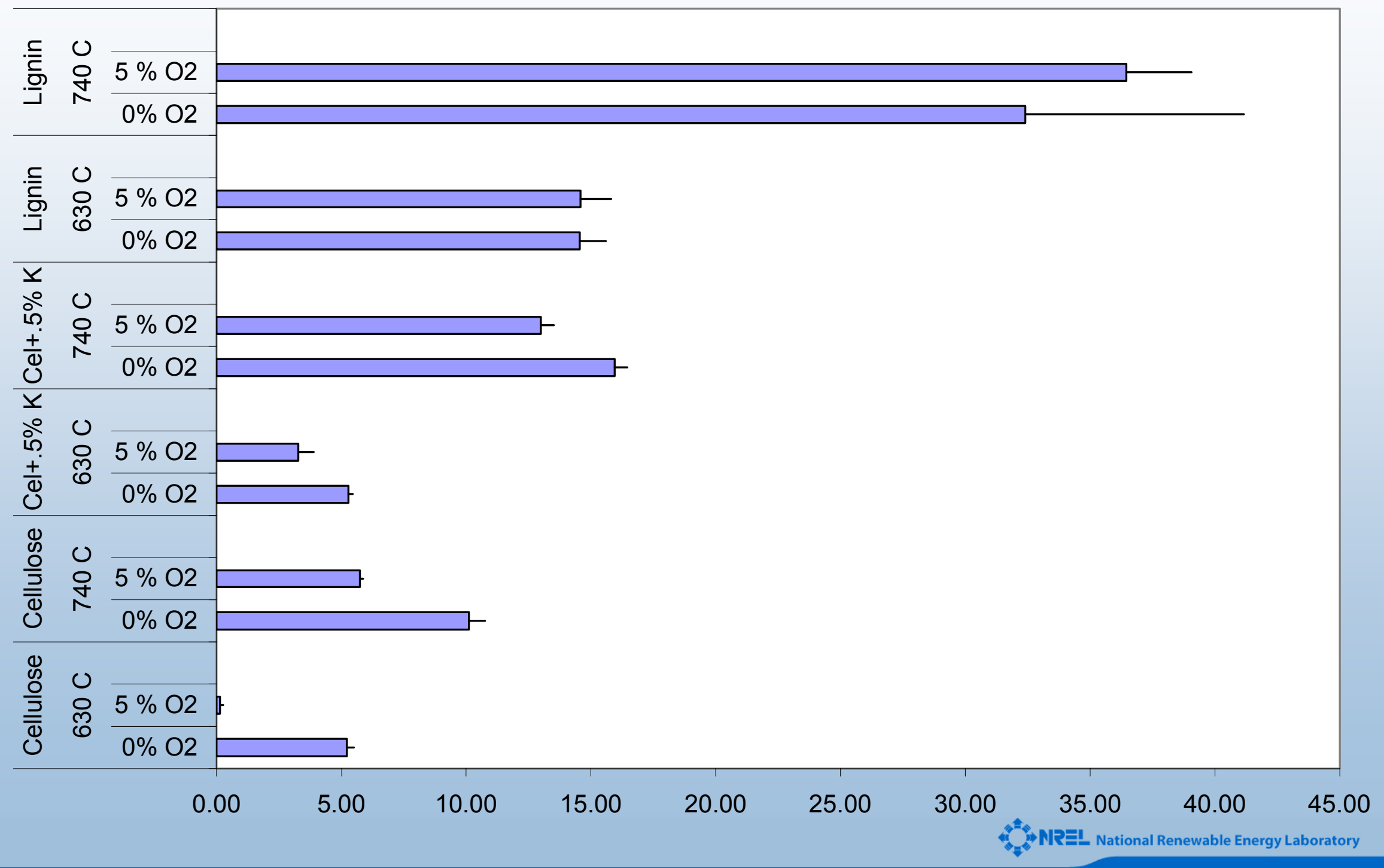




\section{Oxidative Cracking of Pyrolysis Products}

\section{M/z 28 = CO,ethylene}

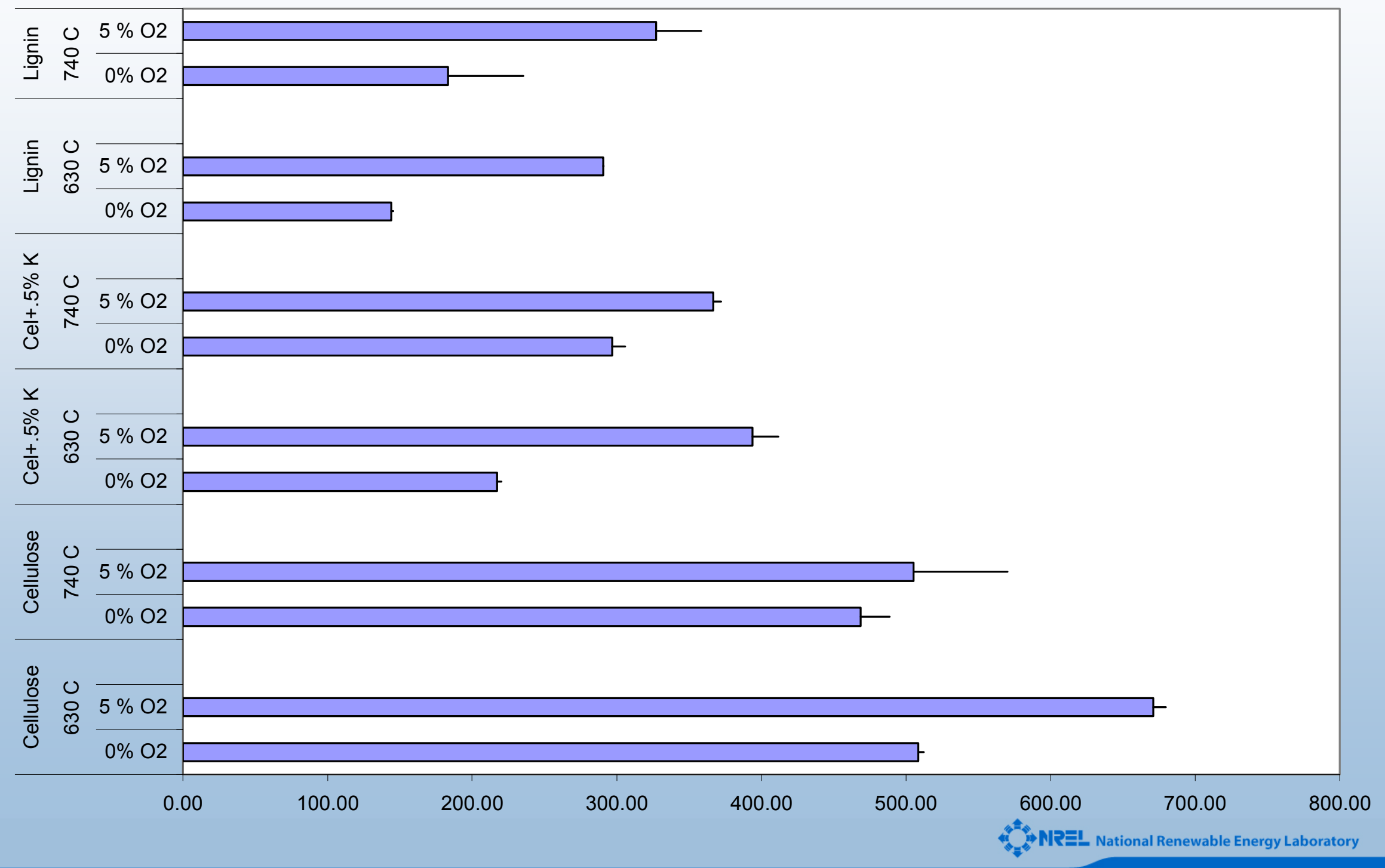




\section{Project Time Line}

\section{\begin{tabular}{|l|l|l|l|l|l|l|l|l|l|} 
FY 2003 & FY 2004 & FY 2005 & FY 2006 & FY 2007 & FY 2008 & FY 2009 & FY 2010 & FY 2011 & FY 2012
\end{tabular}}

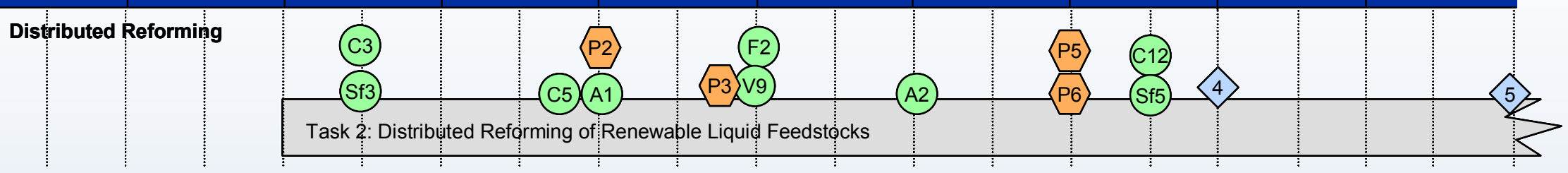

$\begin{array}{ll}\text { Milestones } & \\ 4 & \text { Verify feasibility of achieving } \$ 3.60 / g g e \text { for renewable liquids distributed reforming. } \\ 5 & \text { Down-select research for distributed production from bio-derived renewable liquids. }\end{array}$

Outputs

P2 Output to Delivery, Storage and Fuel Cells: Assessment of fuel contaminant composition.

P3 Output to Systems Analysis and Systems Integration: Impact of hydrogen purity on cost and performance.

P5 Output to Systems Analysis and Systems Integration: Impact of hydrogen purity on cost and performance.

P6 Output to Delivery, Storage and Fuel Cells: Assessment of fuel contaminant composition.

Inputs

C3 Input from Codes and Standards: Preliminary Assessment of Safety, Codes and Standards requirements for the hydrogen delivery infrastructure.

Sf3 Input from Safety: Safety requirements and protocols for refueling.

C5 Input from Codes and Standards: Completed hydrogen fuel quality standard as ISO Technical Specification.

A1 Input from Systems Analysis: Complete technoeconomic analysis on production and delivery technologies currently being researched to meet overall Program hydrogen fuel objective.

F2 Input from Fuel Cells: Research results of advanced reformer development.

V9 Input from Technology Validation: Final report on safety and O\&M of three refueling stations.

A2 Input from Systems Analysis: Initial recommended hydrogen quality at each point in the system.

C12 Input from Codes and Standards: Final hydrogen fuel quality standard as ISO Standard.

Sf5 Input from Safety: Safety requirements and protocols for refueling. 


\section{Safety}

- NREL's Thermochemical Users Facility as a Biomass Hydrogen Resource

- Process Control Development

- Best Practices Training Opportunities

- Ten years of Biomass-to-Hydrogen Lab and Engineering Performance Data 